\title{
TRATAMENTO CIRÚRGICO DE TUMOR ODONTOGÊNICO CERATOCíSTICO COM POSTERIOR INSTALAÇÃO DE IMPLANTE: RELATO DE CASO CLÍNICO
}

Felipe Silva PERALTA, Kleber Lisboa ARAÚJO, Jill Guilherme QUADROS, Antônio Eugênio MAGNABOSCO NETO

O Tumor Odontogênico Ceratocístico (TOC) é um cisto benigno, porém agressivo. Surge a partir dos restos celulares da lâmina dentária, e cerca de $60 \%$ dos casos são diagnosticados em indivíduos entre 10 a 40 anos. A mandíbula é acometida em $60 \%$ a $80 \%$ dos casos, principalmente na região de ramo e corpo. O presente trabalho tem como objetivo relatar um caso clínico de TOC tratado cirurgicamente e proservado durante oito anos. Paciente do sexo feminino, 20 anos, compareceu ao ambulatório de Cirurgia e Traumatologia Bucomaxilofacial do Hospital Municipal São José, para avaliação dos terceiros molares. Após avaliação clinica e radiográfica, verificou-se a presença de extensa área radiolúcida em região de corpo e ângulo de mandíbula, envolvendo os dentes 37 e 38. Inicialmente, realizou-se punção aspirativa da lesão, que possibilitou o diagnóstico de TOC. Posteriormente, foi realizada ressecção total da lesão e exodontia dos dentes envolvidos. Após um ano de acompanhamento clínico e radiográfico, foi instalado um implante osseointegrado na região do segundo molar inferior esquerdo. $O$ caso foi proservado através de radiografia panorâmica por um período de oito anos sem recidiva local. Com isso, podemos concluir que o tratamento cirúrgico do TOC e a posterior instalação do implante foram eficazes.

Palavras-chave: Cistos Odontogênicos; Recidiva; Patologia Bucal. 